\title{
Propagação vegetativa de samambaia gigante - Angiopteris evecta (G. Forst.) Hoffm. ${ }^{(1)}$
}

\author{
LUIZ ANTONIO FERRAZ MATTHES(2); ROBERTA PIERRY UZZO(2); ANTONIO CARLOS DE CARVALHO(3)
}

\begin{abstract}
RESUMO
A samambaia gigante (Angiopteris evecta (G. Forst.) Hoffm.) pode ser propagada por meio das aurículas que ocorrem na base da fronde, que devem ser retiradas das frondes mais velhas e plantadas em recipientes contendo substrato leve, mantidas permanentemente irrigadas, em locais sombreados. Após aproximadamente oito meses, os primeiros brotos começam a emergir. Com um ano e meio a dois da muda formada, ela pode ser plantada em local definitivo.

Palavras chave: Marattiaceae, pteridófitas, samambaia, aurícula, propagação.
\end{abstract}

\section{ABSTRACT \\ Vegetative propagation of giant fern - Angiopteris evecta (G. Forst.) Hoffm.}

The giant fern (Angiopteris evecta (G. Forst.) Hoffm.) can be propagated through the auricles that occur at the base of the frond, they should be removed from the older fronds and planted in containers with lightweight substrate and kept permanently irrigated on shady sites. After about eight months, the first buds begin to emerge. After a year and a half to two the seedling can be planted in permanent location.

Keywords: Marattiaceae, pteridophyta, ferns, auricles, propagation.

A família Marattiaceae compreeende os gêneros Angiopteris, Archangiopteris, Christensenia, Danaea, Macroglossum, Marattia e Protomarattia.

São pteridófitas verdadeiras muito primitivas com ancestrais no período carbonífero. É uma samambaia ornamental, praticamente acaule, cujas folhas (fronde) podem atingir até oito metros de comprimento e tem sua origem na Polinésia, na Melanésia, na Micronésia, na Austrália e Nova Guiné.

A samambaia gigante pode ser utilizada em paisagismo de grandes áreas, e por ser de grande porte, deve ser plantada próxima a locais onde ocorra umidade, como lagos e riachos.

A espécie estudada vem sendo cultivada no Instituto Agronômico (IAC) em Campinas, e foi introduzida dos viveiros do Sítio Burle Marx, localizado na cidade do Rio de Janeiro.

\section{Angiopteris evecta}

Sua estrutura apresenta rizoma desenvolvido, raízes e estipe da folha suculentos, aurículas na base do estipe bem desenvolvidas, sendo duas por estipe, que são persistentes após a morte da folha (Figura 1).

As aurículas são estruturas carnudas suculentas em forma semelhante a uma orelha que nascem na base das folhas de Angiopteris (Figura 2) e Marattia. São tecnicamente chamadas de estípulas. Além do tecido meristemático apical, que ocorre também na base da folha e em cada uma das aurículas, estas aurículas permanecem vivas e persistem ligadas ao tronco (rizoma) por muitos anos após a morte da fronde. As aurículas podem atuar como mecanismo de sobrevivência se o meristema apical da planta for destruído (JONES, 1987).

$\mathrm{Na}$ face inferior da fronde, ocorrem os esporângios que são agrupados em soros.

\section{Propagação vegetativa}

A propagação vegetativa pode ser feita por divisão de touceiras ou pelo plantio de aurículas velhas.

Normalmente, $A$. evecta não se apresenta entouceirada, mas, quando isso ocorre, a touceira toda pode ser dividida e as mudas plantadas em recipientes grandes ou mesmo diretamente no solo. É necessária uma irrigação abundante, mantendo a planta em lugares sombreados e iluminados, no entanto, ela também pode se desenvolver em locais de meia sombra com condições de solo encharcado.

O modo mais comum de propagação é pelo plantio de velhas aurículas. Entretanto, alguns produtores de mudas cortam, com instrumentos bem afiados, a base da folhas, maduras ou senescentes, logo abaixo das aurículas, englobando parte do rizoma, separando desse modo parte do rizoma, base da folha com as duas aurículas. O estipe da fronde deve ser cortado a $0,5 \mathrm{~m}$ de comprimento, podendo conter parte das pinas ou não. Esta estrutura deve ser plantada a uma profundidade tal que as partes superiores das aurículas fiquem levemente expostas.

O meio mais fácil e que não danifica a planta mãe, é o plantio individual das aurículas, que podem ser separadas ou não. Elas devem ser separadas das folhas na primavera ou início do verão, e postas para brotar em recipientes in-

\footnotetext{
(1) Recebido para publicação em 12/12/2010 e aceito em 12/05/2011.

(2) Pesquisador científico, Centro de Horticultura, Instituto Agronômico (IAC), Av. Barão de Itapura, 1481, CEP 13012-970, Campinas/SP. E-mails: matthes@iac.sp.gov.br, rpuzzo@iac.sp.gov.br

(3) Técnico de Apoio à Pesquisa, Centro de Horticultura, Instituto Agronômico (IAC), Av. Barão de Itapura, 1481, CEP 13012-970, Campinas/SP. Email: accarvalho@iac.sp.gov.br
} 
dividuais em substrato leve, ou em musgo de floricultura (esfagno), ou em mistura de solo e areia em partes iguais ou mesmo em areia e turfa na proporção de 3:1, devendo ser mantidos à sombra em lugares quentes e com irrigação abundante.

Seis a doze meses após o plantio começam a emergirem as primeiras folhas e eventualmente podem produzir uma ou duas plantas (Figura 3 ).

Após as mudas formadas, elas podem ser plantas em solos encharcados ou não, mas há necessidade de umida- de ou irrigação constante.

\section{REFERÊNCIAS}

JONES, D.L. Encyclopaedia of Ferns. Portalnd: Ed. Timber Press, 1987, 433p.

http://www.issg.org/database/species/ecology. asp? $\mathrm{si}=1550 \& \mathrm{fr}=1 \&$ sts $=\&$ lang $=\mathrm{EN}, \quad$ acessado em $14 / 02 / 2011$

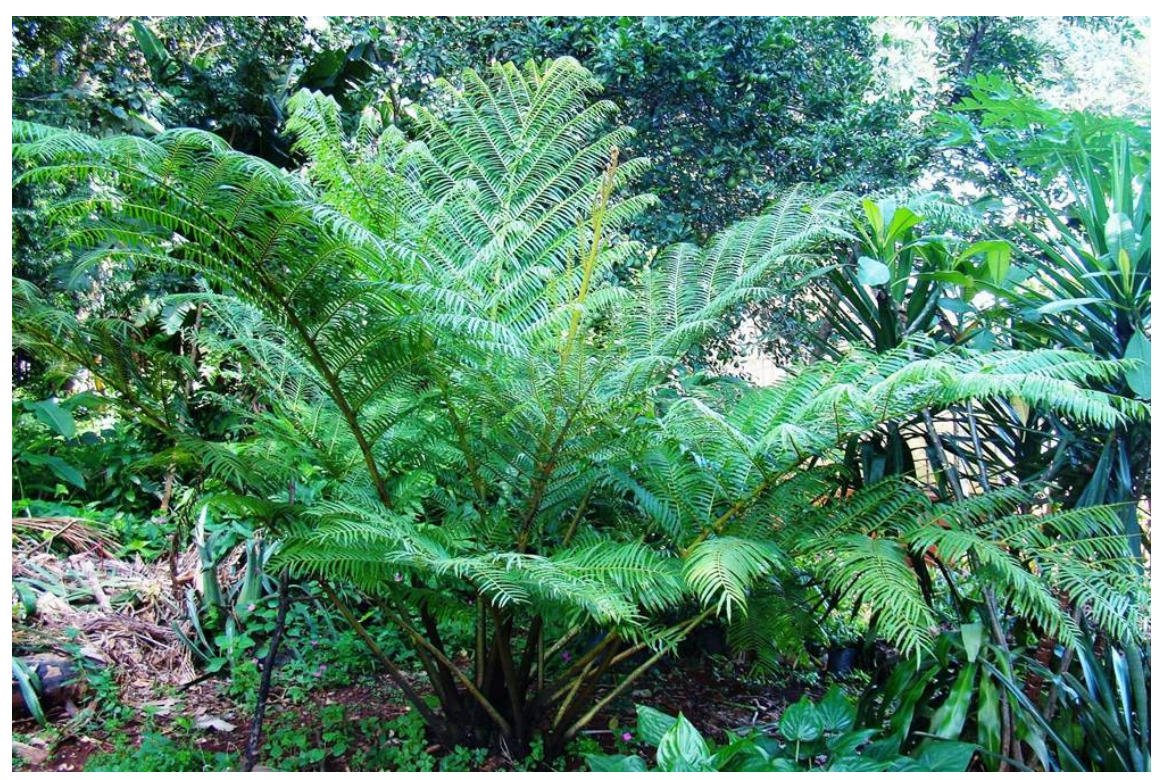

Figura 1. Angiopetris evecta.

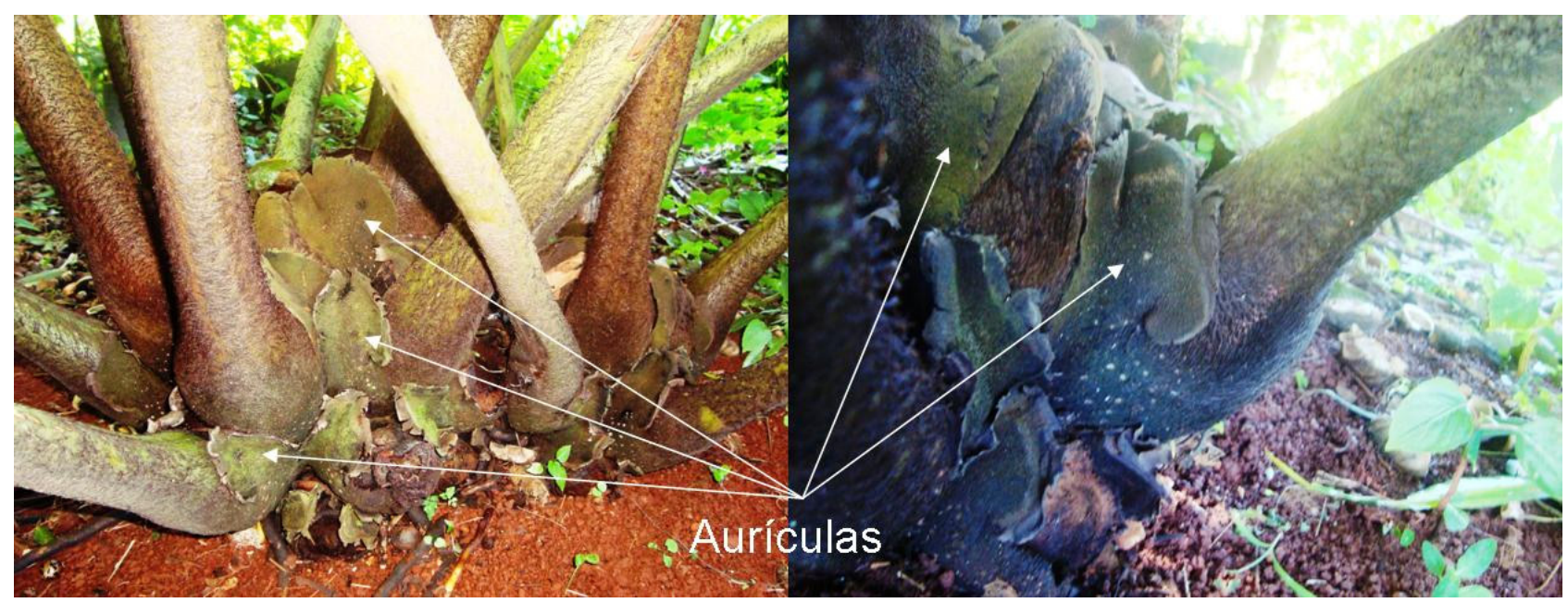

Figura 2. Aurículas nas bases das frondes. 


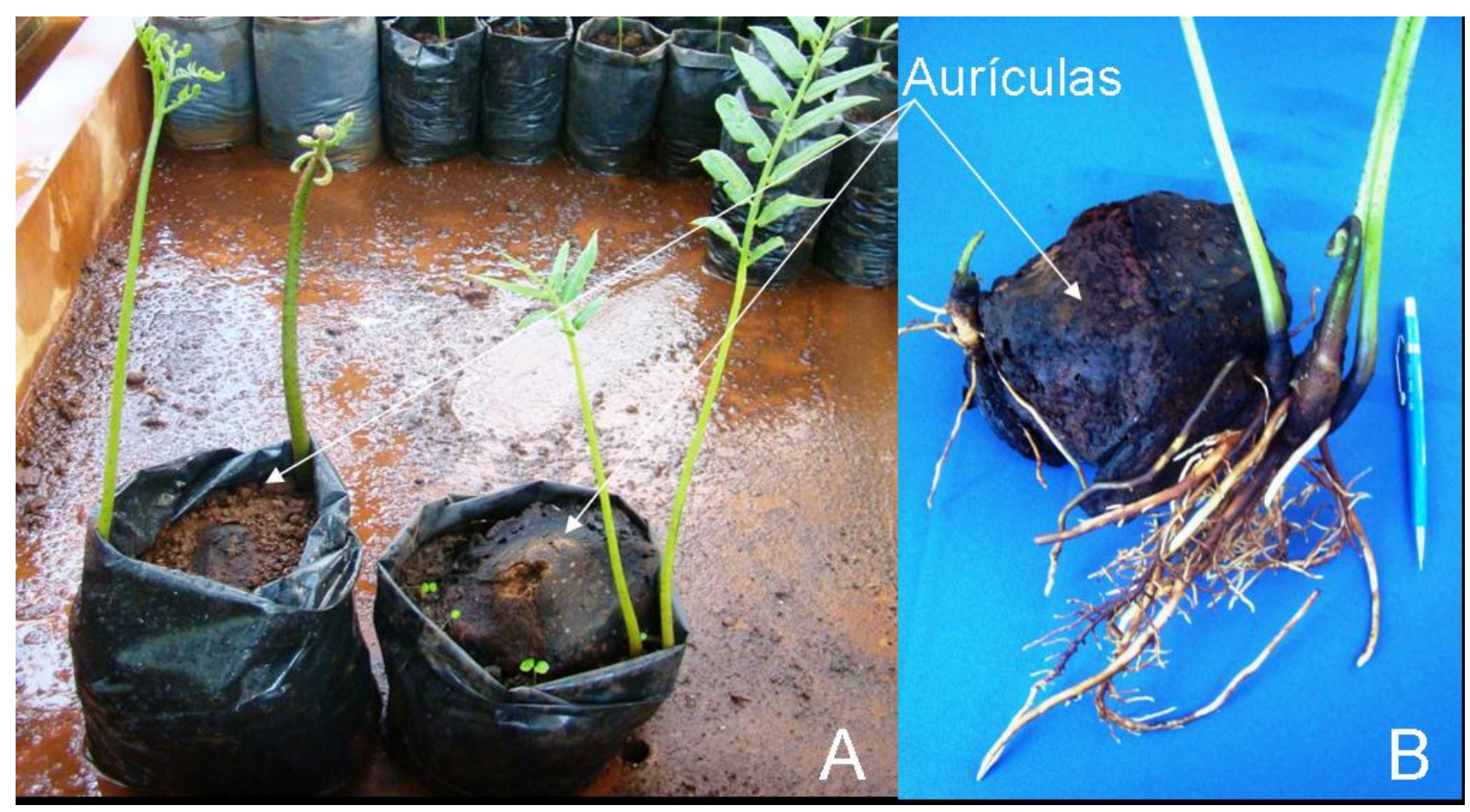

Figura 3. A - Aurículas plantadas em recipientes plástico em brotação com cinco meses de idade. B - Detalhe de aurículas em brotação mostrando o desenvolvimento radicular. 